\title{
O DIREITO À SAÚDE SOB A ÓTICA DA METATEORIA DO DIREITO FRATERNO
}

\author{
Lígia Daiane Fink ${ }^{1}$ \\ Charlise Paula Colet Gimenez ${ }^{2}$
}

\begin{abstract}
RESUMO
Contextualiza-se o debate ora apresentadono cenário da sociedade contemporânea (multicultural), a qual é desafiada dentro do contexto das transformações sociais e das evoluções do ser humano diante do mundo globalizado. Nessa perspectiva, o presente artigo, a partir do método de abordagem hipotético-dedutivo, objetivarepensar o direito à saúde e buscar o reconhecimento das diferenças,apresentando o Direito Fraterno com o intento de efetivar e proteger o direito à saúde.Portanto, o Direito Fraterno indica novos rumos para a complexidade da sociedade contemporânea, uma vez quese fundamenta em uma análise transdisciplinar da sociedade e de seus fenômenos sociais.
\end{abstract}

Palavras-chave: Direitos Fundamentais; Direito à Saúde; Reconhecimento; Direito Fraterno.

\section{THE RIGHT TO HEALTH THROUGH THE FRATERNAL LAW PERSPECTIVE}

\begin{abstract}
This debate is presented in the scenario of contemporary (multicultural) society, which is challenged within the context of the social transformations and the evolutions of the human being in the globalized world. In this perspective, the present article, based on the hypothetical-deductive method of approach, aims to rethink the right to health and recognize the differences, presenting the Fraternal Law in order to effect and protect the right to health. Therefore, the theoretical frameworks of Fraternal Law indicate new directions for the complexity of contemporary society, since it is based on a transdisciplinary analysis of society and its social phenomena.
\end{abstract}

Kew-words: Fundamental Rights; Right to health; Recognition; Fraternal Law.

\section{CONSIDERAÇÕES INICIAIS}

\footnotetext{
${ }^{1}$ Mestranda em Direito pela Universidade Regional Integrada do Alto Uruguai e Missões(URI), Campus Santo Ângelo-RS, vinculada à linha de pesquisa Políticas de Cidadania e Resolução de Conflitos. Estudante no grupo de Pesquisas CNPQ - Conflito, Cidadania e Direitos Humanos, liderado pelo Prof. Dr. João Martins Bertaso e pela Prof ${ }^{a}$ Dra. CharliseColet Gimenez da mesma Universidade. Bacharela em Direito pelas Faculdades Integradas Machado de Assis(FEMA), de Santa Rosa-RS. Especialista em Docência do Ensino Superior pela Faculdade de Educação e Tecnologia da Região Missioneira(FETREMIS) de São Paulo das Missões-RS. Especialista em Direito Penal, Econômico e Tributário pela mesma Faculdade. Pós-graduanda em Direito Previdenciário e Direito do Trabalho pela InstitutoCenecista de Ensino Superior(IESA) de Santo Ângelo-RS. Funcionária Pública Municipal. E-mail: ligia_daia@hotmail.com

${ }^{2}$ Doutora em Direito pela Universidade de Santa Cruz do Sul - UNISC; Docente do Programa de Pós-Graduação stricto sensu em Direito, Mestrado e Doutorado da Universidade Regional Integrada do Alto Uruguai e das Missões, campus de Santo Ângelo/RS, e do Curso de Graduação em Direito, também da mesma universidade; Santo Ângelo, Rio Grande do Sul, Brasil, charliseg@ santoangelo.uri.br.
}

Revista de Direito Sociais e Políticas Públicas | e-ISSN: 2525-9881 | Salvador | v. 4 | n. 1 | p. 160 - 179 | 
O direito à saúde no Brasil, dever do Estado, assegurado pela Constituição Federal de 1988 em seu artigo 196 há mais de 28 anos, o que revela que o ordenamento jurídico brasileiro protege os Direitos Humanos que, por sua vez, integram a ordem jurídica internacional, sendo a saúde um direito relevante. O Estado brasileiro assegura a inviolabilidade do direito à vida, tendo no princípio da dignidade da pessoa humana um de seus fundamentos, assim, todos os cidadãos têm direito à saúde.

Contudo, este direito ainda não se constitui de fato em acesso aos bens e serviços no âmbito do Sistema único de Saúde (SUS), pois para garantir o que preconizam as normas constitucionais, os cidadãos têm de recorrer ao Poder Judiciário, a fim de garantir seus direitos, provocando a judicialização da saúde.

Destarte, sob o enfoque de proteger os princípios e garantias constitucionalmente assegurados, além de proteger o Estado e sua ordem econômica contra a judicialização "desmedida" é de se apontar que se faz necessário uma nova forma de "pensar" o Direito, como também as políticas públicas, para que assim sejam assegurados os direitos e os deveres entre cidadãos e Estado em diferentes situações de conflito, pois a decisão jurídica influencia nas decisões coletivas tomadas pelo sistema político e, em alguns casos, não observa a Política de Assistência Farmacêutica, causando impactos no orçamento, interferindo nas ações dos poderes autônomos, como também diretamente na vida e até mesmo morte das pessoas.

Por isso, o presente texto tem por objetivo apresentar o Direito Fraterno como meio de transformação e reflexão sobre o papel dos sistemas sociais em uma sociedade globalizada, posto que o direito à saúde deve ser universalmente reconhecido. Nesse contexto, uma das tarefas do Direito Fraterno é atentar para a responsabilidade de que cada pessoa tem, de respeitar e reconhecer o outro, como também seus direitos. Na sociedade contemporânea nunca houve tanto direito a ter direitos, contudo, o acesso efetivo a esses direitos, muitas vezes, se dá pela exclusão ou não acesso do outro ou de muitos outros, como é o caso da judicialização da política de saúde.

Assim, apresenta-se o Direito Fraterno como nova perspectiva ao estudo dos problemas sociais, em especial, aos que se referem às políticas de reconhecimento e efetiva inclusão do outro (não em uma inclusão excludente), um direito não violento e universal.

\section{A CONQUISTA DOS DIREITOS FUNDAMENTAIS: A PROTEÇÃO DODIREITO À SAÚDE PELO ESTADO BRASILEIRO}


Os direitos fundamentais são frutos de conquistas históricas, ou seja, nascidos em certas circunstâncias, caracterizados por lutas em defesa de novas liberdades contra velhos poderes, surgem de modo gradual, ao longo do tempo. Tais direitos estão elencados nos textos constitucionais dos países democráticos, como fiel contrato social que atribui aos Estados o dever de planejar políticas públicas, sendo que a concreção desses direitosenvolve uma série de medidas imperativas por parte do Estado(BOBBIO, 2004).

A coexistência entre as formas de Estado de Direito e a efetivação do Estado Social exigem uma postura regulatória por parte dos Estados. Compreender esta relação de participação, direitos e acessos é sem dúvida desafiadora e necessária para compreender os problemas implícitos que atingem a sociedade na contemporaneidade. Nesse sentido, Bobbio reflete a respeito da difícil coexistência entre as formas do Estado de Direito e os conteúdos do Estado Social, cuja compreensão é importante para entender os problemas subjacentes ao desenvolvimento do Estado Contemporâneo:

Uma definição de Estado Contemporâneo envolve numerosos problemas derivados
principalmente da dificuldade de analisar exaustivamente as múltiplas relações que
se criaram entre o Estado e o complexo social e de captar, depois, os seus efeitos
sobre a racionalidade interna do sistema político. Uma abordagem que se revela
particularmente útil na investigação referente aos problemas subjacentes ao
desenvolvimento do Estado contemporâneo é a da análise da difícil coexistência das
formas do Estado de Direito com os conteúdos do Estado Social.Os direitos
fundamentais representam a tradicional tutela das liberdades burguesas: liberdade
pessoal, política e econômica. Constituem um dique contra a intervenção do Estado.
Pelo contrário, os direitos sociais representam direitos de participação no poder
político e na distribuição da riqueza social produzida. A forma do Estado oscila,
assim, entre a liberdade e a participaçãa (E. FORSTHOFF, 1973). [...] enquanto os
direitos fundamentais representam a garantia do status quo, os direitos sociais, pelo
contrário, são a priori imprevisíveis. (BOBBIO, 1998, p. 401).

No plano histórico, o referido autor sustenta que a afirmação dos direitos do homem deriva de uma radical inversão de perspectiva, característica da formação do Estado moderno, na representação da relação política, ou seja, na relação Estado/cidadão ou soberano/súditos, relação esta que cada vez mais é vista como os direitos dos cidadãos não mais súditos, pois para que a sociedade seja compreendida é preciso entender e analisar os indivíduos que compõe a mesma (BOBBIO, 2004).

Flávia Piovesan ao analisar o movimento de internacionalização dos direitos humanos, preceitua que: 
O movimento de internacionalização dos direitos humanos deflagrou-se no Pós Guerra, em resposta às atrocidades cometidas ao longo do Nazismo. Se a Segunda Guerra significou a ruptura do valor dos direitos humanos, o Pós-guerra deveria significar sua reconstrução. (PIOVESAN, 2006 apud CARVALHO, 2007, p. 11).

Em 1948 houve a sistematização da Declaração Universal dos Direitos Humanos a qual foi adotada e proclamada pela resolução 217 A (III) da Assembleia Geral das Nações Unidas, em 10 de dezembro de 1948, em que se elencaram os direitos relacionados à preservação da vida e da dignidade, os quais pressupõem o acesso à saúde e sua promoção pelos Estados. A partir da Declaração Universal da Organização das Nações Unidas (ONU), verifica-se uma nova fase na história dos Direitos Humanos, caracterizada pela universalidade simultaneamente abstrata e concreta, através da positivação na seara internacional, dos direitos fundamentais reconhecidos a todos os seres humanos (SARLET, 2015).

O problema fundamental em relação aos direitos do homem hoje, não é tanto o de comprová-los, mas sim de como preservá-los; assim, esta questão, de certa forma, não é filosófica, mas política. Nessa perspectiva, pode-se dizer que, não se trata de saber quais são esses direitos, uma vez que o fundamento já foi resolvido pela ONU, mas sim, de como garanti-los, pois apesar de todas as declarações, estes direitos são continuamente violados, onde o homem não consegue muitas vezes efetivar tais garantias (BOBBIO, 2004).

Os direitos fundamentais no âmbito de reconhecimento nas primeiras Constituições escritas são o produto peculiar (ressalvado certo conteúdo social característico do constitucionalismo francês) do "pensamento liberal burguês do século XVIII, de marcado cunho individualista, surgindo e afirmando-se como direitos do indivíduo frente ao Estado, mais especificamente como direitos de defesa, demarcando uma zona de não intervenção do Estado e uma esfera de autonomia individual em face de seu poder" (SARLET, 2015, p. 46).

Os direitos fundamentais são direitos através do Estado, ou seja, através das políticas públicas o Estado garante os interesses coletivos e individuais, como expõe Andreas Krell:

[...] os Direitos Fundamentais Sociais não são Direitos contra o Estado, mas sim direitos através do Estado, exigindo do poder público, certas prestações materiais. São Direitos Fundamentais do homem-social dentro de um modelo de Estado que tende cada vez mais a ser social, dando prevalência aos interesses coletivos antes que os individuais. O Estado mediante leis parlamentares, atos administrativos e a criação real de instalações de serviços públicos, deve definir, executar e implementar, conforme as circunstâncias, as chamadas 'políticas sociais'(de educação, saúde, assistência, previdência, trabalho, habitação) que facultem o gozo efetivo dos direitos constitucionalmente protegidos (KRELL, 2002 p. 19-29 apud BAHIA, p. 4). 
Nesse contexto, é direito do cidadão a obtenção de prestações positivas do Estado, as quais ultrapassam a mera discricionariedade administrativa. Ademais, os direitos sociais são delimitadores fundamentais nas decisões constitucionais e políticas. De tal maneira, tais direitos visam à melhoria das condições de vida dos cidadãos tidos como hipossuficientes, no afã de atingir a tão sonhada igualdade social, o que, evidentemente, perpassa pela devida concretização do direito à saúde a que alude o texto constitucional brasileiro (BAHIA, 2014).

Relacionando-se a saúde de modo direto à qualidade de vida, ela não pode ser conceituada de forma inerte, pois se inclui em nosso contexto social, no qual o Estado tem o poder/dever de programar, com prestações positivas, ações que promovam a vida digna do cidadão, lhes proporcionando uma vida saudável (BAHIA, 2014).

O direito à saúde até o nascimento do constitucionalismo moderno, por meio da Organização das Nações Unidas, esteve vinculado apenas à existência de doenças. As ações em saúde se davam apenas diante de uma moléstia grave, que afetava grande número de pessoas e, consequentemente, o meio econômico, tendo em vista a queda de produção em virtude de falecimentos e/ou afastamentos, onde eram pensadas e oferecidas algumas preocupações diante dos fatos que ali ocorriam (CARVALHO, 2007).

Em 1946, o conceito de saúde foi ampliado pela Organização Mundial da Saúde, deixando de ser apenas curativa, mas preventiva, referindo que a "saúde é o completo bemestar físico, mental e social e não apenas a ausência de doenças”, velando a vida e consequentemente a democracia, a igualdade, o respeito, desenvolvimento dentre outros. “Assim, a boa qualidade de vida não está apenas vinculada a questões médicas, mas também a moradia, educação, meio ambiente, proteção da família, do trabalhador, morte digna, informação, não ter fome, assistência social, segurança e outros que venham a surgir, visto que não são taxativos, mas apenas enumerativos e progressivos” (CARVALHO, 2007, p.17).

No Brasil, o movimento de consolidação do setor primário na saúde ganha velocidade a partir da década de 80, com o fechamento do ciclo de industrialização propiciado pelo projeto nacional desenvolvimentista que orientou a ação estatal desde os anos 30 (ELIAS, 2004). Mas apenas com a Constituição de 1988, os direitos fundamentais tiveram inovações de significativa importância. Afinal, pela primeira vez na história do constitucionalismo pátrio a matéria foi tratada com seu devido valor, dada a extrema relevância destes direitos (SARLET, 2015).

A CF/88, cujo artigo $1^{\circ}$ consagra que a República Federativa Do Brasil, constitui-se em um Estado Democrático de Direito, tendo como princípio fundamental a dignidade da 
pessoa humana e corolário deste princípio é o direito à vida e o direito à saúde, os quais devem ser assegurados a todos os cidadãos em território nacional.

O Direito à saúde é direito fundamental e deve ser assegurado pelo Poder Público, conforme o que dispõe o artigo 196 da CF/88: "A saúde é direito de todos e dever do Estado, garantido mediante políticas sociais e econômicas que visem à redução do risco de doença e de outros agravos e ao acesso universal e igualitário às ações e serviços para sua promoção, proteção e recuperação" (BRASIL, 1988).Para corroborar com o artigo 196 da CF/88, sancionou-se a Lei n. ${ }^{\circ}$ 8.080, de 19 de setembro de 1990, a qual dispõe sobre as ações e serviços em saúde, e estabelece no caput do artigo $2^{\circ}, \S 1^{\circ}$ e artigo $3^{\circ}, \S$ único o que segue:

\begin{abstract}
Art. $2^{\circ}$ A saúde é um direito fundamental do ser humano, devendo o Estado prover as condições indispensáveis ao seu pleno exercício.

Parágrafo $1^{\circ} \mathrm{O}$ dever do Estado de garantir a saúde consiste na formulação e execução de políticas econômicas e sociais que visem a redução de riscos de doenças e de outros agravos e no estabelecimento de condições que assegurem acesso universal e igualitário às ações e aos serviços para a sua promoção, proteção e recuperação.

Art. $3^{\circ}$ Os níveis de saúde expressam a organização social e econômica do País, tendo a saúde como determinantes e condicionantes, entre outros, a alimentação, a moradia, o saneamento básico, o meio ambiente, o trabalho, a renda, a educação, a atividade física, o transporte, o lazer e o acesso aos bens e serviços essenciais. (Redação dada pela Lei n ${ }^{\circ} 12.864$ de 2013)

Parágrafo único. Dizem respeito também à saúde as ações que, por força do disposto no artigo anterior, se destinam a garantir às pessoas e à coletividade condições de bem-estar físico, mental e social (BRASIL, 1990).
\end{abstract}

Destarte, a saúde pública corresponde ao setor de interesse do Estado, pois se vincula a direito humano e é essencial a outros direitos humanos, como a vida, a dignidade, a igualdade e o desenvolvimento. No Brasil, a saúde é naturalmente pública, em razão de ser responsabilidade do Estado, podendo ser explorada pela iniciativa privada, todavia, sob regulamentação e fiscalização do ente estatal, em que pese, no Brasil, seja objeto de política pública (CARVALHO, 2007).

$\mathrm{O}$ princípio da dignidade da pessoa humana e o direito à vida elencados na $\mathrm{CF} / 88$, pressupõem que o direito à saúde é um direito fundamental e deve ser plenamente assegurado pelo poder público, em caso de omissão, deve ser compelido a proceder sua efetiva realização.Nesse viés, os cidadãos recorrem à prestação jurisdicional individual ou coletivamente, demandando do Estado o cumprimento do preceito constitucional, sendo que essas demandas podem resultar em um judiciário que decide politicamente sem a estrutura necessária para atuar com a lógica, o ritmo e a prática política do sistema político, formulador e executor das políticas públicas (OLIVEIRA, 2015). 
Tais demandas estão cada vez mais exacerbadas, o que passou a ser chamado de judicialização da saúde. Conforme dispõe Oliveira que:

[...] decisões são fundamentadas no que relatam sobre a situação e a condição do indivíduo, decidindo por fornecimento de medicamentos, em alguns casos, sem observar a Política de Assistência Farmacêutica, causando impactos importantes no orçamento, uma vez que os recursos financeiros são previstos e definidos para um período de gestão; assim, as decisões judiciais acabam interferindo nas ações de poderes autônomos (CHIEFFI; BARATA, 2009). O judiciário tem tratado o direito à saúde como disputa entre Estado e indivíduo (OLIVEIRA, 2015, p. 530).

Em estudo recentemente realizado, publicado na Revista do Centro Brasileiro de Estudos de Saúde concluiu que a judicialização da política de saúde em âmbito nacional tem maior ocorrência em quatro regiões do País, indicando o cidadão brasileiro como protagonista no exercício de sua cidadania, o qual abandona o status de cidadão de papel e assume o status de cidadão de direito, pleiteando do Estado o cumprimento de seu dever (OLIVEIRA, 2015).

Ainda, foi divulgado na Revista, que as maiores concentrações de demandas judiciais na saúde são no Rio de Janeiro, Minas Gerais, Rio Grande do Sul e Pernambuco, além de ser constatado que a judicialização ocorre em todo território nacional e também está acontecendo em todo o mundo.

Dessa forma o sistema começa a apresentar sintomas graves de insustentabilidade, vítima do excesso de ambição da falta de critérios e de voluntarismos diversos, conforme aponta o atual Ministro do Superior Tribunal Federal, Luis Roberto Barroso:

[...] Por um lado, proliferam decisões extravagantes ou emocionais, que condenam a Administração ao custeio de tratamentos irrazoáveis - seja porque inacessíveis, seja porque destituídos de essencialidade -, bem como de medicamentos experimentais ou de eficácia duvidosa, associados a terapias alternativas. Por outro lado, não há um critério firme para a aferição de qual entidade estatal - União, Estados e Municípios - deve ser responsabilizada pela entrega de cada tipo de medicamento. Diante disso, os processos terminam por acarretar superposição de esforços e de defesas, envolvendo diferentes entidades e mobilizando grande quantidade de agentes públicos, aí incluídos procuradores e servidores administrativos. Desnecessário enfatizar que tudo isso representa gastos, imprevisibilidade e desfuncionabilidade da prestação jurisdicional (BARROSO, 2009, p. 35).

A normatividade das disposições constitucionais estabeleceu novos parâmetros para o Constitucionalismo, os quais são frutos de uma importante conquista no Brasil, sendo que o judiciário pode e deve intervir em determinadas situações, envolvendo direitos sociais, em especial o direito à saúde. Todavia, essas intervenções possuem várias críticas, quanto ao ativismo judicial nesta matéria, como preceitua Barroso: 
[...] Pode-se entender que a melhor forma de otimizar a eficiência dos gastos públicos com saúde é conferir a competência para tomar decisões nesse campo ao poder executivo, que possui uma visão global tanto dos discursos disponíveis, quanto das necessidades a serem supridas [...] Talvez a crítica mais frequente seja a financeira, formulada sob a denominação "reserva do possível". As políticas públicas de saúde devem seguir a diretriz de reduzir as desigualdades econômicas e sociais. Contudo, quando o Judiciário assume o papel de protagonista na implementação dessas políticas, privilegia aqueles que tem acesso qualificado à justiça, seja por conhecerem seus direitos, seja por poderem arcar com os custos do processo judicial (BARROSO, 2009, p. 45 e SS.).

Para Ana Paula Barcelos, o fato é que o jurista, e muito menos o juiz, dispõe de elementos ou condições para avaliar, sobretudo em demandas individuais, a realidade da ação estatal como um todo, pois envolvendo-se com a solução de casos concretos - que poderia ser denominado microjustiça- o juiz fatalmente deixa de atender necessidades relevantes para o atendimento das demandas ilimitadas: a macrojustiça. "Ou seja: ainda que fosse legítimo o controle jurisdicional das políticas públicas, o jurista não disporia do instrumental técnico ou de informação para levá-lo a cabo sem desencadear amplas distorções no sistema de políticas públicas globalmente consideradas”. (BARCELOS, 2006, p. 47 apud BARROSO).

Importante salientar no que tange a proteção dos direitos humanos, constitucionalmente assegurados que a judicialização é uma das formas mais demoradas, onerosas e lentas de resolução de conflitos, prejudicando muitas vezes os cidadãos e o Estado, os quais estão vulneráveis a interesses que visam potencializar lucros, muitas vezes por meio da prescrição irracional de fármacos e o estímulo à busca de tratamentos inovadores, não contemplados pelas políticas públicas.

O impacto dessas demandas judiciais proferidas pelo judiciário vem aumentando gradativamente, tornando-se exacerbada, como podemos ver no exemplo com gastos em remédios abaixo: "De 2006 a 2010, o gasto do Ministério da Saúde com remédios via demanda judicial cresceu 1.611\%. Saiu de R \$ 7,7 milhões para R 132 milhões. No Paraná, o panorâmico é parecido: dos $\mathrm{R}$ \$ 61 milhões usados para adquirir medicamentos, $58 \%$ ou $\mathrm{R}$ \$ 35,7 milhões foram comprados por ordem de um juiz" (BOREKI, 2011, apud, RAMOS, CHAI, 2014).

À vista disso, observa-se que o tema judicialização da saúde é tratado tanto nacionalmente, quanto mundialmente, consequentemente os países estão buscando alternativas para solucionar ou minimizar o grande problema da judicialização, por exemplo, na Espanha, onde a Mediação como alternativa ao processo judicial já é sistematizada e resulta na resolução extrajudicial dos conflitos decorrentes da prestação de serviços sanitários, 
proporcionando às partes a solução da controvérsia, sem imposição de uma decisão, evitando assim a possibilidade do conflito terminar no Poder Judiciário (CAYÓN DE LAS CUEVAS, 2010, apud OLIVEIRA, 2015).

Cayón afirma que os sistemas extrajudiciais estão sendo elevados no direito sanitário como um meio alternativo e especialmente adequado para a prática de resolução de conflitos nesta seara, uma vez que são meios mais rápidos econômicos e eficazes, como dispõe:

\begin{abstract}
Los conflictos por defectuosaasistenciasanitariahan sido tradicionalmente abordados enEspaña a través del sistema judicial. No es este el momento de abordar los problemas endémicos que padece ennuestro país laadministración de Justicia, cuya sempiterna crisis, como ladel teatro, se ha convertido en cita yaclásica, pero síconstituyelapretensión de este trabajoefectuar una aproximación indiciaria a los sistemas extrajudiciales de resolución de conflictosenelámbitosanitario. En este sentido, lasventajas de los denominados ADR (alternative dispute resolution) para laresolución de conflictos por mala praxisasistencialresultan, a nuestrojuicio, evidentes. En primer término, y estoes decisivo tanto para el paciente como para elprofesional implicado, se gana en rapidez y agilidad frente a la tradicional lentituddelproceso judicial. En segundo lugar, laheterocomposición extrajudicial suele ser gratuita para elusuario frente a los importantes gastos delprocesojurisdiccional. Asimismo, laresolución a través de instrumentos alternativos puedesuponer una importante reducción tanto de loscostesburocráticos, judiciales y de gestión, como del importe de laindemnización que suele menor que la que hipotéticamentepudieraobtenerseen sede judicial. Del mismo modo, creemos que laaplicación de los ADR a losconflictosasistencialesmejora y favorecelarelación clínica y, enfin, permite laadopción de una solución que huye de losparámetrosculpabilísticostradicionalescontribuyendo a laeliminación de prácticas de medicina defensiva. Esta última tendencia, que podemos calificar como "huida de laculpabilización", se ha ido progresivamenteasentadoen países sanitariamente avanzados, como Suecia, Nueva Zelanda, Dinamarca, Finlandia, Noruega o Estados Unidos, enlos que vienenaplicándose, bajo diferentes fórmulas y variantes, un sistema de responsabilidadsin falta. (CAYÓN DE LAS CUEVAS, 2010, p. 184, 185).
\end{abstract}

Destarte, analisando as insuficientes respostas do Poder Judiciário, na realização das práticas de cidadania, dos direitos fundamentais e de pacificação social, notável é que se faz necessária uma mudança nos mecanismos de resolução de conflitos. Nesse viés no próximo tópico será abordado o conflito (seja entre pessoas ou contra o Estado), como também a perspectiva fraterna, consoante à efetivação do direito à saúde.

\title{
2 A METATEORIA DODIREITO FRATERNO ENQUANTO PROPOSTA DE EFETIVIDADE DO DIREITO À SAÚDE
}

A saúde na sociedade contemporânea é considerada como um bem de todos, um direito social inerente à manutenção da vida, contudo, o reconhecimento deste direito e sua eficácia tem sidos discutidos nos dias atuais, pela sua (in)efetividade. Para isso resgata-se aqui 
o conceito de fraternidade e sua relação com o direito à saúde, uma vez que, é preciso buscar uma possibilidade de transformação social concreta, superando o individualismo, construindo uma sociedade fundada nos princípios da igualdade, fraternidade e da dignidade.

Tendo em vista que a diversidade, a diferença e a busca incessante para efetivação de direitos entre as pessoas de uma sociedade estão intrinsecamente ligadas à existência de conflitos, as pessoas vivem a lógica do individualismo e da competição, sendo inerente ao ser humano possuir desejos similares aos dos outros, gerando rivalidade e disputa; momento em que surge o conflito, pois o homem diante desta disputa, já não possui a capacidade de percepção que há espaço para ele como também para os demais.

Spengler e Gimenez (2013, p. 131) referem que "o conflito manifesta-se como um enfrentamento entre dois seres ou grupos que revelam uma intenção hostil a respeito do outro". Nesse viés, o conflito busca transpor/acabar com a resistência do outro, buscando a dominação da outra parte, com o intuito de impor uma solução, seja com argumentos racionais, muitas vezes utilizando a violência, seja com ameaças, por isso, o conflito é sempre um procedimento contencioso, onde os adversários são tratados na maioria das vezes como inimigos.

Neste linear, percebe-se que o indivíduo não pode fugir da situação de conflito, sem que renuncie seus próprios direitos, assim, ao assentir o conflito, permite que seja reconhecido pelos demais, uma vez que, o conflito pode ser construtivo, estabelecendo um contrato entre as partes, correspondendo aos respectivos direitos e acarretando a construção de vínculos de equidade e justiça entre as pessoas de uma ou entre comunidades (COLET, 2009, p. 52).

Diante da sociedade cosmopolita e multicultural contemporânea, encontram-se os seres humanos, na presençade uma crescente juridicização do Direito, utilizada para traduzir conceitos, ideias e sentimentos,ou seja, para satisfazer as necessidades humanas mínimas, tentandosolucionar esses conflitos.Porém, para que se possam satisfazer tais necessidades, é inescusável que se utilize um instrumento de tratamento de conflitos sem violência, que incentive a paz e o restabelecimento das relações entre os indivíduos (COLET, 2009, p. 53).

Assim, o Direito Fraterno exsurge propondo uma "nova/velha" análise do sistema do direito na sociedade atual, sugerindo uma nova análise do Direito atual, e uma reestruturação das políticas públicas que pretendam uma inclusão literalmente universal. Um princípio esquecido, "prima pobre" da dignidade e da igualdade, a fraternidade, retorna hoje com relevância no sentido de compartilhar, de reconhecer o outro, de identidades globais, de 
mediação, ou seja, é um direito livre de obsessão de uma identidade legitimadora (STURZA; ROCHA, 2015, p. 05).

O principal teórico acerca do Direito Fraterno é Eligio Resta, o qual iniciou seus estudos acerca do tema a partir dos anos 80, e tem sua principal obra apresentada no "Il Diritto Fraterno". Neste sentido, o autor recupera a ideia de fraternidade, retomando um dos princípios da revolução iluminista, que ficou esquecido desde seu enunciado, conforme Vial expõe:

La fraternitàilluministicareimmetteuma certa
dicomplessitànelfreddoprimatodelgiusto sul buono e cerca, appunto,
dialimentaredipassioni calde il clima rigidodellerelazionepolitiche. Ma ha
nellostesso tempo bisognoditrasferireilmodellodell'amicizianella dimensione
dellafraternità, tipicadi una condivisionedidestinigrazieallanascita e
indipendentementedelledifferenze. Per questo ha bisognoditransformarla in codice,
difarneregola; con tutti i paradossi, maanchecontutteleapertureche comporta. Per
questo è "diritto fraterno" che si affacciaallora, in epocailluministica, e vive da quel
momento in poi come condizione esclusa, ma non eliminata, accantonata e presente
nellostesso tempo (RESTA, 2002, p. 07 apud VIAL, 2006, p. 121).

O Direito Fraterno, consoante manifestaEligio Resta, retorna hoje na sociedade contemporânea para re-propor condições que já haviam se apresentado no passado. Atualmente, a sociedade enfrenta uma época em que a forma estatal das pertenças fechadas estão desgastadas, governadas por um mecanismo ambíguo que incluiu os cidadãos, excluindo todos os outros.

Os embates acerca do Direito, de modo geral, encontram-se ancorados na figura de um soberano, ou seja, como figura de efetivação dos direitos; por issodeve haver um soberano, representado, pelos Estados-Nação. Já o Direito Fraterno, propõe uma outra concepção - a fraternidade - sendo que esta difere dos modelos soberanos, uma vez que parte do pacto entre iguais e, desse modo,é considerado(frater - irmão) e não (pater-pai/superior).

Nessaacepção, afirma-se que o Direito Fraterno é uma metateoria ${ }^{4}$, pois se apresenta como uma teoria das teorias, propondo uma nova forma de reconhecimento do Direito na

\footnotetext{
3 “A fraternidade iluminista insere novamente uma certa cota de complexidade no frio primado do justo sobre o bom, e procura, com efeito, alimentar de paixões quentes o clima rígido das relações políticas. Mas há, concomitantemente, a necessidade de transferir o modelo de amizade à dimensão da fraternidade, típica de uma comunhão de destinos derivada do nascimento e independente das diferenças. Assim, há a necessidade de transformá-la em código, de fazê-la regra, com todos os paradoxos, mas também com todas as aberturas que comporta. Por isso é 'direito fraterno' que se configura então, em época iluminista, vivendo, daquele momento em diante, como condição excluída, mas não eliminada, deixada de lado e, ao mesmo tempo, presente" (Tradução livre - VIAL, 2006, p. 121).

${ }^{4}$ Importante definir o conceito de metateoria apresentado no dicionário enciclopédico de teoria e de sociologia de direito: "1. A metateoria é um tipo de atividade que pesquisa (a pesquisa metateórica), os resultados dessa atividade (a 'metateoria'). 2. Pesquisa que tem por objetivo específico as teorias científicas (elas próprias
} 
sociedade atual. De acordo comVial (2006), o Direito Fraterno, sendo uma metateoria, faz uso também da técnica no sentido ambivalente de sua utilização. Destarte, é essencial trazer a ideia de pharmakon,expressão grega utilizada por Eligio Resta, que ao mesmo tempo tem significado de remédio e veneno, dependendo de como éempregada.

Na sociedade contemporânea, é mister pensar o direito a partir de uma visão transdisciplinar, essa transdiciplinariedade significa transgredir e integrar, haja vista que a sociedade atual não é mais aquela definida geograficamente, mas sim uma sociedade de mundo (cosmopolita), uma sociedade multicultural.

Isso posto, o Direito Fraterno prima pela análise transdisciplinar dos fenômenos sociais. A trandisciplinariedade significa, antes de tudo, transgredir - no sentido de buscar os fundamentos e pressupostos nas mais diversas ciências, tentando captar o sentido das ações sociais e jurídicas-; integrar, no sentido de analisar o contexto do todo e não em partes separadas, com o objetivo de reconhecer as diferenças entre os sistemas sociais e/ou ciências, sendo que é a existência dessas diferenças e limitações que permitem uma análise à complexidade do fenômeno-; e ultrapassar - uma vez que é necessário ultrapassar os limites de um saber único, sendo que procurar conhecer é ao mesmo tempo desconhecer-. É nessa acepção que Resta perquiriu e analisou as mais diversas áreas do conhecimento, questionando as verdades, resgatando novos/velhos conceitos(fraternidade), apostando assim, na retomada do Direito Fraterno (STURZA; ROCHA, 2015).

O Direito Fraterno, para Resta, afasta a dominação histórica de um direito fechado nas fronteiras do Estado e busca um espaço de reflexão ligado ao tema dos direitos humanos, mas com outro entendimento, o de que é a humanidade que deve buscar dentro de seu interior o reconhecimento e a tutela, ou seja, os direitos humanos somente podem ser ameaçados pela própria humanidade, esomente podem ser efetivados pela própria humanidade (RESTA, 2004).

Resta refere que o Direito Fraterno pode ser a forma mediante a qual pode crescer um processo de auto-responsabilização dos cidadãos, contudo, este processo somente se dará desde que o reconhecimento do compartilhamento esteja livre da rivalidade destrutiva típica do modelo dos "irmãos inimigos"(RESTA, 2004).

Esse modelo de Direito abandona a fronteira fechada da cidadania e busca uma nova forma de cosmopolitismo que não é apenas representada pelos mercados, mas por uma

consideradas também sob o ponto de vista da atividade e do seu produto) e que tem, como resultado, a produção de uma 'teoria das teorias científicas' (distinção feita em relação a interpretação jurídica - Tarello - entre metateoria como atividade e metateoria como produto)"(ARNAULD, 2000. p. 493). 
emergente necessidade universalista, que demanda respeito aos direitos humanos e que se sobrepõe ao egoísmo dos "lobos artificiais" ou dos poderes informais que governam e decidem à sua sombra. Assim, pode-se falar que o Direito Fraterno vive da falta de fundamentos, anima-se de fragilidades, de apostas, vive de expectativas cognitivas e não de arrogâncias normativas (RESTA, 2004).

Então, a análisedo direito à saúde por meio do Direito Fraterno deve observar os pressupostos básicos desta meta-teoria os quais serão elencados sucintamente:

a) o Direito Fraterno é um direito jurado entre irmãos, homens e mulheres, no sentido de fratersem a imposição de um soberano, mas sim de um pacto em que se decide conjuntamente compartilhar regras de convivência. É o oposto do direito paterno, o qual é imposto por um soberano, porém, a conjuntura fraterna não é contra o pai, ou soberano, mas sim, para uma convivência compartilhada, livre de soberania e da inimizade;

b) é um direito livre de obsessão da identidade que deveria legitimá-lo;

c) oDireito Fraterno encontra-se em um espaço político aberto, livre das limitações políticas e geográficas que justificam seu domínio. A tarefa compartilhada são suas únicas justificativas;

d) questionao direito de cidadania, uma vez que este é, desde sempre, lugar de exclusão; destarte, o direito fraterno volta seu olhar para os direitos humanos, na humanidade como um lugar comum. Não obstante a dimensão ecológica dos direitos humanos, nos leva à conscientização de que os direitos humanos podem ser ameaçados sempre e somente pela própria humanidade, como também, são protegidos somente por esta;

e) o quarto fundamento do direito fraterno é a diferença entre ser homem e ter humanidade, refere que existe uma grande distância entre os dois (ser homem e ter humanidade). Os direitos humanos são lugar de responsabilidade e não de delegação; por isso o direito fraterno é cosmopolita;

f) Outro fundamento essencial do direito fraterno é que ele é um direito não violento, não insere a ideia do inimigo, destituindo o binômio amigo/inimigo. Pois, não se podem defender os direitos humanos enquanto os está violando, assim, a possibilidade de sua existência está no evitar o curto circuito da ambivalência mimética (pharmakon), que o transforma de remédio e doença, de 
antídoto em veneno. A minimização da violência leva a uma jurisdição mínima, conciliando em conjunto e mediando com pressupostos de igualdade e diferença;

g) o direito fraterno é contra os poderes, de todos os tipos, os quais exercem domínio sobre a vida nua, este pressuposto é intricado posto que elimina algumas seguranças, verdades e dogmas;

h) é um direito inclusivo, dado que, escolhe direitos fundamentais e define acesso universalmente compartilhados a bens inclusivos, pretende uma inclusão sem limitações;

i) é a aposta de uma diferença, com relação aos outros códigos que trabalham com o binômio amigo/inimigo, haja vista que o direito fraterno propõe a ruptura desse binômio.

Demonstradas as estruturas do Direito Fraterno, visualiza-se o caráter inclusivo e transdisciplinar deste modelo de direito, o qual rompe as fronteiras fechadas da cidadania e projeta o Direito para uma nova forma de cosmopolitismo. EligioResta, conclui a sua obra, fazendo a seguinte proposta:

O Direito Fraterno, então, vive da falta de fundamentos, anima-se da fragilidade; procura evitar que "deve" ser, e que existe uma verdade que o move. Ao contrário, arrisca numa aposta, exatamente como na aposta Pascal sobre a existência do bem comum: se tivesse existido, o benefício teria sido enormemente maior do que o custo empregado com as próprias contribuições pessoais. No caso em que, ao contrário, não tivesse existido aquilo que se gastou, teria tido um pequeno custo em relação aquilo que poderia ter ganhado. Convém, então, apostar na fraternidade (RESTA, 1996, p. 125).

Assim, uma sociedade fraterna, que aposta na própria humanidade, investe na existência do bem comum, assumindo a existência do inimigo, não pelo seu descarte, deixando-o à margem, mas pelo reconhecimento de que a rivalidade existe dentro de cada um, logo, dentro da própria humanidade. Com esse reconhecimento, a ordem jurídica, deve buscar o desenvolvimento universal, superando a lógica individualista, seja individual, de grupo, classe ou etnia.

Nesse ínterim a possibilidade do Direito Fraterno ser uma nova aposta da efetivação do direito à saúde está alicerçada no desafio apresentado por Baratta, que sugere a construção de um novo saber, uma nova forma de pensar e fazer o Direito, que ultrapassa, mas não esquece, os limites dos juristas e não juristas e os limites da ciência do direito frente às demandas que surgem, conforme expõe Vial: 
[...] Perché solo com um grande sforzo teórico e pratico di tutti, giuristi e non, si puògiungereallaconstruzionedi um nuovosaperecollettivo, Del diritto e sul dirittoadeguatoallasituazioneumana Del nostrotempo.(...) Nuovirischi, come quelliricollegabiliallaingegneria genética, alla energia nucleare, allosfrutamentodellericorsenaturali, al trattamentodellescorie e dei rifiuti, al traffico, all'uso dei mezzidicomunicazione e dielaborazione dei dati, fanno parte oramai dei connotatistrutturalidellasituazioneumana e dell'ecosistema. Essi sono ancheilluogospeciale in cui, nell'incontrotra La (Riga illegibile), puòemergere una nuova forma dipensare e di fare Il diritto ${ }^{5}$ (BARATTA, 2006, p. 64-65, apud, VIAL, 2009 , p. 70)

É imperioso identificar que na sociedade contemporânea possuímos muito mais direitos, dos quais efetivamente podemos usufruir, a inclusão universal existente, se dá na maioria das vezes pela exclusão do direito do outro,"a inclusão se dá pela exclusão; a possibilidade de acesso ao direito de ter direito à saúde se dá muitas vezes, não através do sistema de saúde, mas pelo sistema judiciário, ou ainda pior, por favores políticos ou de amizade"(VIAL, 2016, p. 997, grifo do autor).

O Direito Fraterno é uma alternativa de efetivação do direito à saúde uma vez que reconhece o outro, como o "outro eu"- meu irmão - alguém com quem se pactue algo. Pois, para que todos tenham direito à saúde é necessário efetivar o pacto pela vida, é essencial que todos envolvidos participem para efetivação de uma política de saúde adequada, de sua gestão até sua implementação (COSTA; FORTES; DIEHL, 2014).

Assim, o direito à saúde pode ser resgatado e efetivado, pois não é suficiente apenas dizer que a saúde é dever do Estado e direito do cidadão, mas sim, é preciso criar condições para efetivação desses direitos, o que ocorrerá somente com políticas públicas que respeitem as diferenças locais e apresentem uma estrutura global (COSTA; FORTES; DIEHL, 2014).

$\mathrm{Na}$ perspectiva do direito fraterno desaparece a figura de um soberano que explora, surgindo a figura de um soberano que perde sua superioridade, passando a ser um irmão, um "outro eu"; superar as ambivalências emotivas e escolher o caminho do universalismo, recebendo e incluindo o outro, significa ser amigo da humanidade. $\mathrm{O}$ amigo da humanidade “endereça sua amizade a uma ideia, um projeto, no qual conta o respeito por qualquer outro,

\footnotetext{
5 "Porque somente com um grande esforço teórico e prático de todos, juristas ou não, poder-se-á alcançar a construção de um novo saber coletivo, do direito e sobre o direito adequado à situação humana do nosso tempo (...). Novos riscos, como aqueles vinculados às emissões na atmosfera ou na água, na engenharia genética, na engenharia nuclear, no mau uso dos recursos naturais, no tratamento dos resíduos industriais e do lixo, no tráfico, no uso dos meios de comunicação e de elaboração de dados, fazem parte, atualmente, das conotações estruturais da situação humana e do ecossistema. Esses são também o lugar especial no qual, do encontro entre a (linha elegível), pode emergir uma nova forma de pensar e de fazer o direito.’[Tradução Livre]
} 
e, assim, por si mesmo. A amizade pela humanidade é sensibilidade estética [...], mas é, sobretudo, dever e responsabilidade [...]"(RESTA, 2004, p. 49).

Nesse contexto, desafia-se o particularismo, a amizade pela humanidade, instaurando-se um jogo lingüístico, colocando em foco, a relação entre parte e todo, ou seja, entre particularismo e universalismo. Assim,

\begin{abstract}
Amigo da humanidade é, portanto, o indivíduo moral e racional que, conscientemente, conhece os riscos, mas, gandhianamente, aposta na existência de um bem comum, que é o bem da humanidade em si mesmo. Paradoxalmente, amigo da humanidade é quem compartilha o sentido de humanidade e dela se sente parte, assumindo, também, a existência do inimigo; não o demoniza, nem o descarta, jogando-o em "outro" mundo, mas assume inteiramente o seu problema. A rivalidade reside, portanto, em nós mesmos, dentro da própria humanidade; assim, o amigo da humanidade não é simplesmente o oposto do inimigo, mas é algo diverso que, graças à sua diversidade, é capaz de superar o caráter paranoico da oposição (RESTA, 2004, p. 50).
\end{abstract}

Nota-se que o Direito tradicionalmente construído - forma estatal de pertenças fechadas, com um sistema que inclui cidadãos excluindo outros -, já não consegue responder adequadamente aos desafios impostos pela atualidade, sendo necessária uma nova forma de pensar e fazer o Direito.

Deve haver uma superação da individualidade moderna na sociedade contemporânea, isto é, deve-se construir uma sociedade de interesses e responsabilidades em relação aos direitos iguais de sermos humanos e tutelar os mesmos e o direito à saúde deve ser reconhecido universalmente, não apenas nos limites do Estado-Nação, pois é um bem comum de toda a humanidade

Portanto, a ruptura da cultura do inimigo, exige que se reconheça o outro (e suas diferenças) como a si mesmo, pressuposto este da condição humana; nesse ínterim, a fraternidade pode ser utilizada como meio de possibilitar o reconhecimento do outro e de sua alteridade, constituindo assim, o Direito Fraterno, como uma nova fora de promoção dos direitos humanos, valorizando a relação como iguais, mas respeitando suas diferenças, sendo assim um direito inclusivo, pois considera as pessoas apenas pelo fato de serem humanos (GIMENEZ; PIAIA, 2017).

Neste linear, uma das metas do Direito Fraterno é fazer refletir sobre a responsabilidade de cada um de nós, que compartilha o caráter de humanidade. "É assim que se apresentam os pressupostos do Direito Fraterno, que tratam de uma nova dimensão para o entendimento dos direitos humanos e, portanto o direito à saúde” (COSTA; FORTES; DIEHL, 2014). 
O direito à saúde sob a perspectiva da metateoria do Direito Fraterno deve ser pensado como acesso aos serviços de saúde e bem comum de toda a humanidade, haja vista que a fraternidade vai ao encontro do bom e harmônico convívio com os outros, é um direito que é para todos e aceito e/ou proposto por todos. Na sociedade contemporânea em que estamos incluídos universalmente, onde todos tem direito a acesso a todos bens e serviços, em especial o direito à saúde, deve-se refletir como vivemos esta "inclusão", que pode até mesmo promover a morte, onde esta poderia ser evitada (VIAL, 2016).

Assim, a metateoria do Direito Fraterno enquanto nova proposta para efetividade do direito à saúde na sociedade multiculturalestá alicerçada na construção de um novo saber coletivo, do Direito e sobre o Direito adequado à realidade humana contemporânea, possibilitando novas perspectivas para a sociedade, utilizando a fraternidade como princípio constituinte das relações sociais,em defesa do reconhecimento do outro, de suas diferenças, direitos, assim sendo, da humanidade como lugar comum.

\section{CONSIDERAÇÕES FINAIS}

O presente artigo teve como escopo a apresentação da sociedade contemporânea multicultural eos desafios para o reconhecimento das diferenças diante das evoluções do mundo globalizado.

Nesse sentido, no primeiro tópico, dissertou-se acerca da promoção da dignidade da pessoa humana e a proteção da saúde pelo Estado, a historicidade, seus principais objetivos, como também os principais desafios e sintomas de (in)sustentabilidadeque a sociedade contemporâneaestá enfrentando,uma vez que, para garantir os direitos assegurados na Constituição, em especial o direito à saúde, os cidadãos invocam à prestação jurisdicional irrestritamente, ocasionando a judicialização da política.

Em contraponto à ineficácia das atuais políticas de reconhecimentoé apresentada a metateoria doDireito Fraterno, como nova perspectiva na construção de uma proposta para a solução dos problemas que surgem com o não reconhecimento dos direitos; uma vez que, este (Direito Fraterno), é um direito inclusivo, não violento, pauta-se no acesso universalmente compartilhado, onde todos seres humanos usufruem de igual condição.

Em uma sociedade que se torna cada vez mais complexa e que com os processos de evolução aumenta sua multiculturalidade,são necessárias políticas democráticas que garantam 
e potencializem os direitos humanos a nível universal, em especial o direito à saúde ora elencado, sendoum grande desafio da sociedade contemporânea.

Portanto, o Direito fraterno, enquanto reconhecimento do outro na perspectiva do direito à saúde, estáalicerçado na fraternidade, supera as ambivalências emotivas, opta pelo caminho do universalismo, recebendo e incluindo o outro, sendo amigo da humanidade, superando a individualidade moderna presente na sociedade e construindo uma sociedade de interesses e reponsabilidades para com o outro - direitos iguais de sermos humanos-.

$\mathrm{O}$ direito à saúde sob a perspectiva do Direito Fraterno deve ser pensado como acesso comum para toda a humanidade, devendo se refletir como a humanidade está vivendo a inclusão universal de direitos que ora estamos inseridos, "inclusão" esta que quandosolicitada indevidamente ou desmedidamente, pode até promover a morte do outro ou de outros, sendo que poderia ser evitada, com uma reflexão, reconhecendo o outro também como sujeitos de direitos, tornando a humanidade um lugar comum de todos.

\section{REFERÊNCIAS BIBLIOGRÁFICAS}

BAHIA, Carlos José Amaral; ABUJAMRA, Ana Carolina Peduti; MARTA, Taís Nader. A proteção jurídica na ordem nacional e o direito fundamental ao acesso a medicamentos. Disponível em: < http://www.rkladvocacia.com/arquivos/artigos/ art_srt_arquivo20100728201015.pdf>. Acesso em: 21 out. 2014.

BARROSO, Luís Roberto. Da falta de efetividade à judicialização excessiva: direito à saúde, fornecimento gratuito de medicamentos e parâmetros para a atuação judicial. Disponível em: $<$ http://www. tjmg. jus. br/portal/conhecimento-juridico/artigosjuridicos/detalhe-122. htm>. Acesso em: 16 out. 2016.

BERTASO, João Martins; SANTOS, André Leonardo Copetti. Diálogo e Entendimento: direito e multiculturalismo e políticas de cidadania e resoluções de conflito. Campina/SP: Editora Millenium, 2012.

BOBBIO, Norberto. A era dos direitos. Rio de Janeiro: Elsevier, 2004.

Dicionário de política. 11. ed. Brasília: Editora Universidade de Brasília, 1998. 1. v.

BRASIL. Lei no 8.080, de 19 de setembro de 1990. Dispõe sobre as condições para a promoção, proteção e recuperação da saúde, a organização e o funcionamento dos serviços correspondentes e dá outras providências. Disponível em:

<https://www.planalto.gov.br/ccivil_03/LEIS/L8080.html>. Acesso em: 22 out. 2014.

CARVALHO, Patrícia Luciane de. Patentes farmacêuticas e acesso a medicamentos. São Paulo: Atlas, 2007. 
COLET, Charlise Paula. A valorização do ser humano a partir das matrizes teóricas do direito fraterno e da justiça restaurativa: o tratamento de conflitos como forma de exercício da cidadania. Revista Direito e Justiça - Reflexões Sociojurídicas - n. 12, p. 49-70, mar. 2009. Acesso em: <http://gajop.org.br/justicacidada/wp-content/uploads/JusticaRestaurativa-Como-Forma-de-Exercicio-da-Cidadania.pdf>. Acesso em: 15 set. 2017.

COPETTI SANTOS, André Leonardo; LUCAS, Doglas Cesar. A (in) diferença no direito. Porto Alegre: Livraria do Advogado, 2015.

COSTA, Marli Marlene Moraes da; FORTES, Francielli Silveira; DIEHL, Rodrigo Cristiano. $O$ ativismo judicial como instrumento de efetivação dos direitos humanos e fundamentais: uma análise da garantia do direito frente à meta-teoria do direito fraterno. Coletânea de direito sanitário e saúde coletiva, v. 2, Criciúma, SC: UNESC, 2014. Disponível em:http://dspace.unesc.net/bitstream/1/2639/1/Colet\%C3\%A2nea\%20Direito\%20Sanit\%C3\% A1rio\%20e\%20Sa\%C3\%BAde\%20Coletiva\%20v2.pdf\#page=99. Acesso em 13 set. 2017.

CUEVAS, JoaquínCayón de las. Implantación de mecanismos de resolución extrajudicial de conflictos por mala praxisasistencial: ventajas y posibilidades de articulación jurídica. Revista de Administraciónsanitariasiglo XXI. Vol. 8, Número 1: p. 183-198. Espanha: Rev.Adm. Sanit., 2010. Disponível em:

<https://dialnet.unirioja.es/ejemplar/319826>. Acesso em 16 de out. 2016.

ELIAS, Paulo Eduardo. Estado e saúde: os desafios do contemporâneo. Disponível em: <http://www.scielo.br/pdf/spp/v18n3/24777.pdf>. Acesso em: 21 out. 2014.

FERREIRA, Roberto; MACHADO, Costa; FERRAZ, Ana Candida da Cunha. Constituição Federal interpretada. 3. ed. São Paulo: Manoele, 2012.

GIMENEZ, Charlise P. Colet; PIAIA, ThamiCovatti.O tratamento dos conflitos da pósmodernidade pelo Direito Fraterno: crises, migrações e insurgências. Revista Novos Estudos Jurídicos, v. 22, n.01, p. 75-98,Jan/Abr. 2017. UNIVALI, ITAJAÍ. Disponível em: <https://siaiap32.univali.br//seer/index.php/nej/article/view/10633>. Acesso em 24 set.2017.

LUCAS, Douglas César. Multiculturalismo e o debate entre liberais e comunitaristas: em defesa da interculturalidade dos direitos humanos. Sequiência: Estudos Jurídicos e Políticos,v.30, n.58, p.101-130, 2009. Disponível em:

<https://periodicos.ufsc.br/index.php/sequencia/article/view/14877> Acesso em: 20 set. 2017.

; OBERTO, LeoniceCadore. Redistribuição versus reconhecimento: apontamentos sobre o debate entre Nancy Fraser e Axel Honneth. Revista de Estudos Constitucionais, Hermenêutica e Teoria do Direito, v. 2, n. 1, p. 31-39, 2010. Disponível em: <http://www.revistas.unisinos.br/index.php/RECHTD/article/view/4773>. Acesso em 20 set. 2017.

; SCHNEIDER, Bruna Dallepiane. Multiculturalismo: Identidades em Busca de Reconhecimento. Revista Direito em Debate, v. 18, n. 31, 2013. Disponível em: <https://revistas.unijui.edu.br/index.php/revistadireitoemdebate/article/view/640>. Acesso em: 20 set. 2017. 
MCLAREN, Peter. Multiculturalismo Crítico. São Paulo: Editora Cortez, 1997.

NUNES, Rizzatto. O princípio Constitucional da dignidade da pessoa humana: doutrina e jurisprudência. 2. ed. São Paulo: Saraiva, 2009.

PIOVESAN, Flávia. O direito internacional dos direitos humanos e o Brasil. Disponível em: <http://www.dhnet.org.br/direitos/militantes/flaviapiovesan/piovesandihbr.html>. Acesso em: 25 de out. 2015.

RESTA, Eligio. O Direito Fraterno. Tradução e Coordenação Sandra Regina Martini Vial. Santa Cruz do Sul: EDUNISC, 2004.

SARLET, Ingo Wolfgang. A eficácia dos direitos fundamentais. 12. ed. Porto Alegre: Livraria do Advogado, 2015.

Dignidade da pessoa humana e direitos fundamentas na Constituição Federal de 1988. 9. ed. Porto Alegre: Livraria do Advogado, 2012.

SILVA, Tomaz Tadeu da. (Org). HALL, Stuart; WOODWARD Kathryn. Identidade e diferença: a perspectiva dos Estudos Culturais. 13. ed. Petrópolis: Vozes, 2005.

SPENGLER, Fabiana Marion; GIMENEZ, Charlise P. Colet. O necessário reconhecimento das formas de tratamento de conflitos como política pública no Brasil. Revista Direito e Justiça, n. 21, p. 126-137, nov. 2013. Disponível em: <https://livros-e-

revistas.vlex.com.br/vid/necessa-reconhecimento-tratamento-conflitos-pola-522447242>. Acesso em: 16 set. 2017.

STURZA, Janaina Machado; ROCHA, Claudine Rodembusch. Direito e Fraternidade: paradigmas para a construção de uma nova sociedade. Disponível em:

<http://publicadireito.com.br/artigos/?cod=601c6bc71c748001>. Acesso em: 16 set. 2017.

VIAL, Sandra Regina Martini. Direito fraterno na sociedade cosmopolita. Revista do Instituto de Pesquisa e Estudos, Bauru, v. 1, n.46, p. 119-134, jul./dez. 2006. Disponível em:<https://bdjur.stj.jus.br/jspui/bitstream/2011/18207/Direito_Fraterno_na_Sociedade_Cos mopolita.pdf>. Acesso em: 16 set. 2017.

Saúde: um direito fundado na fraternidade. Saúde e direitos humanos / Ministério da Saúde. Fundação Oswaldo Cruz, Núcleo de Estudos em Direitos Humanos e Saúde Helena Besserman. - Ano 5, n.5 (2008), Brasília: Editora do Ministério da Saúde, 2009. Disponível em: https://www.nescon.medicina.ufmg.br/biblioteca/imagem/3037.pdf\#page=65. Acesso em 13 set. 2017. 